\title{
Fostering Quality Teaching and Learning in Higher Education through Academic Staff Development: Challenges for a Multi-Campus University
}

\section{E N Cishe (Dr)}

\author{
Walter Sisulu University, Faculty of Education, Private Bag x1, WSU, Eastern Cape \\ Email: ecishe@wsu.ac.za, bandlac@gmail.com
}

Doi:10.5901/mjss.2014.v5n25p272

\begin{abstract}
The National demands on quality and concentration by Higher Education Institutions to meet these demands compromise the provision of quality teaching, thereby hindering the quality of learning. Also, many systems of external quality assurance are cumbersome, bureaucratic and time-consuming for academics and their effect in improving quality is generally not yet conclusively demonstrated. Compliance with external requirements on quality initiatives results to lack of time towards staff development, and in some cases making it difficult for staff development. This paper reports on challenges faced by one Higher Education Institution in promoting the quality of teaching and learning through academic staff development. This is a case study of a multi-campus higher education institution in the Eastern Cape, South Africa. Qualitative interpretive paradigm informed the investigation. Semi-structured interview was conducted with the Teaching Development Consultant coordinating staff development to generate data. Findings revealed that although staff development can enhance quality teaching and learning there are challenges to achieving quality. These challenges are presented in this paper. In conclusion, some recommendations on how quality in teaching and learning can be promoted and maintained through academic staff development are suggested.
\end{abstract}

Keywords: fostering, learning, quality, staff development, teaching.

\section{Introduction}

While universities enjoy rewards for research, both in terms of finance and status, there seem to be no equivalent for teaching and yet universities are required to pay greater attention to improving teaching and enhancing student learning. They need to become more accountable to external bodies for the quality of teaching and learning at their institutions. The National demands on quality and concentration by Higher Education Institutions to meet these demands compromise the provision of quality teaching thereby hindering the quality of learning.

In South Africa quality standards in higher education are ensured by a number of quality assurance bodies which include, amongst others, the Higher Education Quality Committee (HEQC), the Engineering Council of South Africa (ECSA), the Health Professionals Council of South Africa (HPCSA) and the South African Institute for Chartered Accountants (SAICA). Institutions are, therefore, destined to be busy spending over time complying with external accountability requirements with little or time left to innovate in teaching, learning, offering quality teaching and enhancing quality learning. In order to offer quality teaching and enhance quality learning there should be well developed academic staff.

In this paper, I present the research questions; explain quality teaching and learning, academic staff development, how quality of teaching and learning can be enhanced, research methodology, challenges faced in fostering quality teaching and learning, conclusion and recommendations.

\section{Purpose and Objectives}

The aim of this paper was to explore academic staff development as a tool to enhance quality teaching and learning in higher education and presents the challenges faced by a multi-campus university in fostering quality teaching and learning. In order to achieve this aim, the paper sought to answer the following questions:

1. How academic staff development contributes to quality teaching and learning?

2. What strategies are employed in promoting quality teaching and learning?

3. What are the challenges experienced in fostering the quality of teaching and learning? 


\section{Quality Teaching and Learning}

Quality can be understood as fitness for purpose. Because teaching and learning process is complex, there are no straight answers for the quality equation and this paper will not attempt to provide that. Two principles can be used in trying to understand quality. These are identifying student's cognitive development as a major objective of education systems, and the role of education in promoting shared values, responsible citizenship and creative and emotional development (Guttman, 2005).

Biggs (2001) and Tam (2001) define quality as an outcome, a property, or a process in higher education. Quality teaching is understood by Hénard and Roseveare (2012) as the use of pedagogical techniques to produce learning outcomes for students. This involves the effective design of curriculum and course content, a variety of learning contexts and effective assessment of learning outcomes. They see quality teaching important in higher education despite the continuous changes experienced by institutions. It is a part of a global quality approach and of the institutional strategy and should not be isolated from the institutional quality culture.

Quality teaching in higher education is the use of pedagogical techniques to produce learning outcomes for students. It involves several dimensions, including the effective design of curriculum and course content, a variety of learning contexts (including guided independent study, project-based learning, collaborative learning, experimentation, etc.), soliciting and using feedback, and effective assessment of learning outcomes. For quality teaching to be effective, it should involve well-adapted learning environments and student support services. This implies that there should be good teaching. Good teaching leads to quality teaching. Felder and Brent (1999) refer to good teaching as lasting acquisition of the knowledge, skills, and values and it leads to effective learning. In order to enhance student learning there should be focus on quality teaching initiatives. The university should care about teaching and if it wants its teaching to be of good quality, it must value teaching and shows that it matters. Encouraging a quality teaching culture should consist of supporting academics in order to enhance teaching culture among leaders, teachers, students, staff and other stakeholders. Academics should be allowed to discuss about teaching and learning as Gravett and Geyser (2004) argue that teachers who discuss their struggles and seek advice are those who are dedicated to teaching and to their students. These are teachers who regard teaching as a daunting, yet enriching and enjoyable task. Gravett and Geyser (2004) argue that it is the quality of the learning experience that determines successful learning.

Bruening (2011) asserts that an opening speech by the then South African Minister of Education, Prof Asmal, during a conference on higher education curriculum at the University of Pretoria in April 2004 reiterated the government's position and strategic purpose for higher education in South Africa, which is to produce graduates who are well rounded and thoroughly grounded; who are skilled and competent; who are creative, flexible and adaptive to new challenges; who are adept in critical thinking and cultural literacy; who are enabled and empowered to participate fully in their economy, their society and in their world that is rapidly changing. The quality of teaching and learning in higher education institution is, therefore, dependent on having well developed academic staff as it is only well-developed and properly qualified academics that can facilitate successful and quality learning. This means that academics involved in teaching and supporting student learning should be qualified, supported and adequately resourced for that role. The quality of the staff in institutions of higher education is central to the effectiveness of teaching, portrays Fielden (1998). In his paper, Fielden (1998) argues that a high quality and well motivated teaching staff and a supportive professional culture are essential in building excellence. It is not what the lecturer can offer and students learn, but the quality of both teaching and learning. Increasingly, there is a need to view teaching as an intellectual act that contributes to the transformation of knowledge (Boyer, 1990). The presence of the learning content is no assurance that learning will take place. Gravett and Geyser (2004) argue that it is the quality of the learning experience that determines successful learning.

\section{Academic Staff Development}

HEQC (2004: 23) define academic development as 'a field of research and practice that aims to enhance the quality and effectiveness of teaching and learning in higher education, and to enable institutions and the higher education system to meet key educational goals, particularly in relation to equity of access and outcomes. Volbrecht and Boughey (2004) refer to academic development as an open set of practices concerned with improving the quality of teaching and learning in higher education through integrating student, staff, curriculum, institutional and research development. To these authors, quality is a broad term, referring to commitments to social justice, excellence, effectiveness and efficiency.

The report on the survey of directors of academic development in South African universities carried out by Gosling (2009) revealed areas of academic development work that were rated as most important by the largest number of academic directors who participated in the survey. These were grouped into four clusters which were: 
1. provision of staff development activities, notably induction/orientations to teaching courses for new academics and training in use of ICT/e-learning

2. engaging in and promoting research in learning and teachng

3. providing leadership for learning and teaching and implementing strategic direction of their institution

4. Assisting in the development of new courses.

In the areas mentioned above, I regard provision of staff development activities as crucial. This involves providing advice to staff members and providing individual support to academics who experience difficulties in their teaching. Academic staff development is used to represent a range of formal and informal activities aimed at contributing towards academic capacities as scholarly educators and it should be geared to help academics promote student learning. The report by Gosling further revealed that professional development of staff was regarded as an important function of the academic development centres.

It is important that academics are given the opportunity to develop their teaching practice in ways that contribute to maintaining effective and relevant learning by students. It is the responsibility of higher education institutions to provide professional development for its academics aiming at supporting effective learning by students from disadvantaged backgrounds.Academic staff development is not without challenges. Scott (2009) argues that the primary challenge of academic development is to strengthen the academic and professional foundations and at the same time take forward the educational development agenda.

\section{Fostering Quality Teaching and Learning through Academic Staff Development}

Hénard and Roseveare (2012) portray the practice of fostering quality teaching as a multi-level endeavour with one of the levels aimed at encouraging teachers to innovate and adopt learner-oriented focus. These teachers should co-operate with students, colleagues from other departments, and with external stakeholders as members of a dynamic learning community. Pennington and O'Neil (1994) believe that there should be a workable strategy for teaching and learning at an organizational level. To this end, they suggest that organizations should align strategic objectives in teaching and learning in a way to demonstrate how commitment to scholarship and research, flexibility, community regeneration and all similar statements carry over into students' actual experiences of the curriculum. It should be recognized that change in teaching and learning approaches is effective when integrated with appropriate strategies for staff development, curriculum renewal, quality assurance, resource allocation, information technology and the development of the physical and material learning environment (Pennington and O'Neil, 1994: 14). The role of quality assurance and quality control mechanisms is not merely to ascertain whether procedures have been followed, but also to promote curriculum change and to act as reference point for judging the degree to which students experience quality learning in practice.

Hénard and Roseveare (2012) assert that fostering quality teaching presents higher education institutions with a range of challenges at a time when the higher education sector is coming under pressure from many different directions. These pressures include conforming to external demands as presented earlier in this paper. Higher education institutions need to ensure that the education they offer meets the expectations of students and the requirements of employers, both today and for the future. In order to do this, they should foster quality teaching and enhance quality learning. Hénard and Roseveare (2012) further state that institutions should support the enhancement of teaching quality.

Universities in South Africa have different strategies aimed at improving teaching and learning. For instance, Cape Peninsula University of Technology (CPUT) uses Curriculum Officers to improve teaching and learning while Walter Sisulu University (WSU) uses Teaching and Learning Development Consultants to do the same. At WSU, the Centre for Learning and Teaching Development (CLTD) adopted the developmental aspect of quality and became responsible for quality enhancement to learning and teaching (WSU, 2011a). Numerous workshops on facilitation of learning and appropriate methodology were conducted for academic staff but the impact these had on staff development may not be realised.

Strydom, Basson and Mentz (2012) argue that enhancing the quality of teaching and learning is a key strategic focus area in higher education and that accountability demands on higher education institutions that relate to the quality of teaching and learning are increasing. This calls for higher education institutions to find ways of providing evidence in measurable ways of what they are doing to improve teaching and learning (McCormick, 2009 quoted in Strydom, N Basson and M Mentz, 2012).

\section{Methodology}

This is a case study undertaken in a multi-campus higher education institution in the Eastern Cape Province of South 
Africa. The higher education institution has four campuses that cover a distance of over $1000 \mathrm{~km}$ in a round trip. The shortest distance is $130 \mathrm{~km}$ from one campus to another and the longest is approximately $260 \mathrm{~km}$. Staff development is the responsibility of a unit based in one of the campuses. According to Leedy et al. (2005), a case study enables one to have an in-depth investigation of small number of cases. It focuses on one instance (or a few instances) of a particular phenomenon with a view of providing an in-depth account of events, relationships and experiences occurring in that particular instance hence the focus was only on the Teaching Development Consultants. The qualitative interpretive paradigm informed the investigation. This approach was chosen as it is an inquiry process based on building a holistic complex understanding of a social problem. It is characterized by data collection method in a natural setting. Qualitative approach enabled me to approach the subject, probe the setting, and describe perceived realities in a more natural way and in great depth. The participant was interviewed and with his permission the interview was recorded.

\section{Data analysis}

The interview was transcribed word for word trying to understand and make sense of the responses. I listened to the voice recorder and organized the data by breaking it into manageable units, synthesizing it, searching for patterns, discovering what is important to be learnt. The goal was to create descriptive, multidimensional categories, which form a preliminary framework for analysis. Words or phrases or events that appeared to be similar were grouped into the same category. The findings are presented in the section below.

\section{Findings}

In this section I present findings and challenges faced by a multi-campus university in fostering the quality of teaching and learning through academic staff development. It transpired that the institution under study is no different from other national universities whose cultures prefer research activity over teaching. This is a result of the funding formula that is based on throughput rate and research output. The unexpected consequence of this framework may be the lowering of standards in order to improve the completion rates so as to qualify for higher subsidy rates.

The university offers opportunities for academic staff development in the form of workshops that focus on teaching and learning strategies, assessing students, curriculum development, learner guide development and basic e-learning workshops. Academics are also offered an opportunity to register for Post Graduate Diploma in Higher Education and Training (PGDHET) with all costs paid for by the institution. These opportunities are offered through Helpdesk invitation, departmental requests and individual applications. The participant was not sure of the extent to which these opportunities develop academics and contribute to the quality of teaching and learning.

It is the role of CLTD, Human resources (HR) and Heads of Departments (HoDs) to ensure that academics are developed. CLTD liaise with departments on their needs and workshops conducted are based on the needs analysis. These training sessions are aimed at enhancing quality teaching and learning. They are quality assured and those offered by external service provider are registered and accredited by the Skills Education Training Authorities (SETA). Despite the attempts by the institution, academic staff development was hindered by poor attendance of the training sessions by lecturers, non support by HoDs, institutional rules to enforce staff development attendance, none recognition of professional development points benefiting academics professionally and towards promotion.

The institution initiated Vice Chancellor's Awards for excellence in teaching and learning for remarkable improvements in teaching and learning. This involved self-evaluation, peer-reviewing and benchmarking of practices. The aim of these awards was to develop excellent teachers. The participant was concerned that although this was an attempt to develop academics it was only done once due to institutional financial challenges and the continuous changes experienced by institutions. He affirmed that the awards will be revived in the near future as the financial situation has improved

The participant also highlighted the following as challenges in academic staff development. These were the difficulty in aligning institutional policies to foster quality teaching, raising awareness of quality teaching, support for quality teaching at three inter-dependent levels which are institutional, programme and individual. He also highlighted challenges of providing conducive learning environments (libraries, computing facilities) of similar standards and quality in the multi-campuses of the institution due to distance between the campuses. Reference was also made to the different teaching and learning cultures of the campuses.

In so far as enhancing the quality of teaching and learning is concerned, there is lack of resources; there are many academics BUT few teachers (no teaching background). It also transpired that there is lack of academic leadership to drive academic development and lack of formal support towards post-graduate studies, especially PhD. One of the 
causes may be that the institution is said to be financially non-viable with less budget on staff development. Also, a large number of academics, especially junior members of staff are overloaded, teaching many modules and classes as large as 100 and above and this makes it difficult to ensure quality. Finally, staff appraisal which is a crucial element of staff development is not undertaken.

Some measures to overcome the identified challenges were suggested. These include integrating and embedding academic development within learning and teaching practices with accountability measures to the leadership and management of learning and teaching in academic departments. Doing this would ensure that credibility is given to the teaching competence. Also, the scholarship of teaching and learning should be enforced within departments.

\section{Conclusion and Recommendations}

The findings revealed that there were challenges in fostering quality teaching and learning through academic staff development in the multi-campus higher education institution under study.

The various opportunities for staff development were offered but their impact could not be established. The support is in line with Hénard and Roseveare (2012) who state that the enhancement of teaching quality should be supported. The Vice Chancellor's Awards for excellence in teaching and learning meant to develop excellent teachers is in line with Felder and Brent's (1999) idea that the university should care about teaching and if it wants its teaching to be of good quality, it must value teaching and show that it matters. Although the Vice Chancellor's awards was an attempt to develop academics it could not be continued due to institutional financial challenges and the continuous changes experienced by institutions. This is in support of Hénard and Roseveare (2012) assertion that fostering quality teaching presents higher education institutions with a range of challenges at a time when the higher education sector is coming under pressure from many different directions. Scott (2009) in Bitser (2009) also highlighted a challenge of academic development whilst taking forward the educational development agenda.

The challenges discussed in this paper contribute to the decline of the quality of teaching and learning and pressures override an intention to improve teaching and learning.

\section{Recommendations}

Having outlined the challenges in fostering quality teaching and learning through academic staff development, I wish to propose the following recommendations that can be useful:

1. Academics teaching the same modules/courses within and across departments/faculties should serve as critical friends. This will contribute to staff development.

2. The funding framework based on student throughput and research output calls for the re-allocation of the academic workload in that the Professors and senior academics should be allocated $1^{\text {st }}$ year students with large numbers. Doing so would provide junior academics opportunities to conduct research and furthering their studies and at the same time improving the quality of teaching and learning.

3. Academic staff members should be offered an opportunity to attend conferences even if they are not presenting a paper. Staff members who have never read a paper in a conference may not be enthusiastic to do so if they do not observe other academics doing so. Opening up conference attendance offers participating in public consultations and this will contribute to staff development.

4. Compulsory time-off should be set aside for academics to develop themselves.

5. Strategies, including awards for excellence in teaching and learning, research and community engagement should be offered continuously.

\section{References}

Biggs, J. (2001), "The reflective institution: assuring and enhancing the quality of teaching and learning", Higher Education, 41 (3),221238

Boyer, E. (1990). Scholarship reconsidered: Priorities of the Professorate. Princeton, NJ Carnegie Foundation for the Advancement of Teaching.

Bruening T. H. (undated) Reinventing the Teaching Learning Process: Lessons from the University of the North. The Pennsylvania State University Press

Felder, R.M. and Brent, R. (1999) Improving teaching quality in an individual class. Quality Management Journal, 6(2), 9-21.

Fielden, J. (1998) Thematic Debate: "Higher Education Staff Development: A Continuing Mission" ED-98/CONF.202/11.

Gosling, D. (2009) Report on the survey of directors of Academic Development in South African universities. 
Gravett S \& Geyser H (2004) Teaching and Learning in Higher Education. Pretoria: Van Schaik Publishers.

Guttman, (2005) EFA Global Monitoring Report. Education for all. The quality imperative. United Nations Educational, Scientific and Cultural Organization

Hénard, F. and Roseveare, D. (2012) Fostering Quality Teaching in Higher Education: Policies and Practices. An IMHE Guide for Higher Education Institutions. www.oecd.org/edu/imhe

Higher Education Quality Committee, 2004. Improving Teaching and Learning Resource. Pretoria: Council on Higher Education.

Leedy, G. (2005). Planning and design, $7^{\text {th }}$ ed. New Jersey: Merrill Prentice hall.

Pennigton, G. \& O'Neil, M. (1994) Enhancing the Quality of Teaching and Learning in Higher education, Quality Assurance in Education, (3), 13-18, MCB University Press.

Scott, I. (2009). "Academic development in South African Higher Education." In: Bitzer, E. (ed) Higher Education in South Africa. A Scholarly Look Behind the Scenes. Stellenbosch: SUN Media.

Strydom, J.F., Basson N., and Mentz M. (2012) Enhancing the quality of teaching and learning: Using student engagement data to establish a culture of evidence. Pretoria: Council on Higher Education.

Tam, M. (2001), "Measuring Quality and performance in Higher education", Quality in Education, 7 (1), 4-54

Volbrecht, T. and Boughey, C (2004). "Curriculum responsiveness from the margins?

A reappraisal of Academic Development in South Africa." Griesel, H. (ed) Curriculum Responsiveness: Case studies in higher education. Pretoria, SAUVCA: $57-80$.

Walter Sisulu University, 2011a. Strategic Monitoring, Evaluation and Reporting Framework, Mthatha 